\title{
Trauma-Informed: Dependency Court Personnel's Understanding of Trauma and Perceptions of Court Policies, Practices, and Environment
}

\author{
Victoria A. Knoche ${ }^{1}$ (D) Alicia Summers ${ }^{1} \cdot$ Monica K. Miller $^{1}$ \\ Published online: 13 June 2018 \\ (C) Springer International Publishing AG, part of Springer Nature 2018
}

\begin{abstract}
The law and legal processes can affect the psychological and emotional well-being of the people involved. Individuals who are already traumatized can experience stress which triggers prior trauma through court policies, practices, and environment during involvement with the child abuse and neglect court system. However, some courts use trauma-informed policies, practices, and environments which are based on the notion of therapeutic jurisprudence. The purpose of this analysis was to determine if dependency court personnel in larger jurisdictions have differing understandings of trauma, and differing perceptions of court policies, practices, and environment than their counterparts from smaller jurisdictions. Results indicate that smaller jurisdiction personnel have a higher understanding of trauma, as well as perceive themselves to be more trauma-informed in the areas of policy, practice, and environment when compared to larger jurisdiction personnel. Implications are discussed and recommendations from a therapeutic jurisprudence framework are suggested.
\end{abstract}

Keywords Jurisdiction size · Trauma-informed · Therapeutic jurisprudence $\cdot$ Child abuse and neglect court

In 2015 , more than 7 million children were referred to authorities for maltreatment, with child protective services investigating approximately 2.2 million cases (Child Welfare Information Gateway 2017). In 2015, for children 12-17, approximately 2.7 million were victimized in the form of sexual abuse, physical abuse, or psychological maltreatment (Truman and Morgan 2016). By the nature of the allegations against the families, it can be assumed that many individuals in the child abuse and neglect court system are or have been traumatized (Marsh et al. 2016). These same individuals must then endure court processes which may be stressful and trigger prior trauma. For example, court processes may lead to feelings of blame or shame for parenting, having a child physically removed from their parents' care, uncertainty of not knowing when the child will be returned home, or in some cases, where the child is, or when a child is asked to recount their traumatic experience multiple times, to multiple individuals. However, some courts use trauma-informed practices,

Victoria A. Knoche

vknoche@nevada.unr.edu

1 Interdisciplinary Social Psychology, University of Nevada, Reno, 1664 N Virginia St, MS 1300, Reno, Nevada 89557, USA programs, and environments in an attempt to prevent these negative outcomes (Marsh et al. 2016).

The purpose of this analysis was to determine if dependency court personnel have a differing understanding of trauma, as well as perceptions of court policies, practices, and environments depending on the size of their jurisdiction. This might occur due to the amount of trauma experienced by children, families, or staff, volume of cases involving trauma, extent of trauma knowledge, resources available, or types of trauma encountered. Identifying differences in traumainformed policies, practices, and environments between larger and smaller jurisdiction dependency courts could inform court personnel what areas of trauma-informed practices need improved policies or responsive strategies by different size jurisdictions to limit re-traumatization.

\section{Literature Review}

The National Child Traumatic Stress network defines a trauma-informed system as "one in which all parties involved recognize and respond to the impact of trauma stress on those who have contact with the system" (www.nctsn.org). Traumainformed practices can include the use of separate waiting areas for victims and perpetrators, a child friendly area in the 
waiting room, and having the building and courtrooms at a comfortable temperature. Use of these practices vary among jurisdictions because of courthouse site restrictions or lack of knowledge about how to implement trauma-informed practices (Ko and Sprague 2007; Marsh et al. 2016).

\section{Trauma-Informed Practices}

In the United States, $2 / 3$ of children experience some type of traumatic event by age 16 (Substance Abuse and Mental Health Services 2017). Trauma exposure can include witnessing or experiencing domestic violence, community violence, physical or sexual assault, neglect, a life-threatening accident, or disasters (Substance Abuse and Mental Health Services 2017). Such trauma can be particularly troublesome for youth. Youth experience the effects of trauma differently depending on several factors such as their age at time of the trauma, as well as the trauma's frequency and perceived severity (Child Welfare Information Gateway 2015). Although some youth are able to recover from trauma quickly, trauma exposure, especially repeated exposure, can significantly disrupt child or adolescent development and cause long-term consequences (Ko et al. 2008; Pynoos et al. 2006). Continued exposure to trauma can alter psychobiological development in youth, as well as increase the risk of engagement in high-risk behaviors, low academic performance, and difficulties in family and peer relationships (Child Welfare Information Gateway 2015; Ko et al. 2008). Exposure to trauma can be a factor in mental health issues (McCall-Hosenfeld et al. 2014) and traumatic stress is linked with an increase in use of mental health services and involvement in the child welfare and juvenile justice systems (Chapman et al. 2006; Garland et al. 2001; Ko et al. 2008).

Up to $90 \%$ of juveniles who are involved in the justice system report exposure to some type of traumatizing event (Dierkhising et al. 2013). Of justice-involved youth, $70 \%$ meet criteria for some mental health disorder and nearly $30 \%$ meet criteria for post-traumatic stress disorder (PTSD) (Dierkhising et al. 2013). Justice-involved youth report higher rates of trauma exposure than nonjustice-involved youth; this trauma typically begins early in life, and occurs in multiple contexts and over time (Dierkhising et al. 2013). Youth who report maltreatment are at higher risk of criminal or delinquent involvement throughout adolescence and adulthood (Dierkhising et al. 2013; Smith and Thornberry 1995; Widom and Maxfield 1996). Chronic or frequent maltreatment is associated with chronic or severe delinquent behavior and this relationship holds across ethnicity and gender (Dierkhising et al. 2013; Smith and Thornberry 1995; Widom and Maxfield 1996). Other forms of trauma exposure such as domestic violence, community violence, and traumatic loss are also linked to justice involvement and delinquency (Dierkhising et al. 2013; Foy et al. 2012; Kerig et al. 2009; Wood et al. 2002).

Within the juvenile justice system, many court personnel are interested in preventing or at least limiting trauma by effectively helping those who have a history of trauma exposure (Marsh et al. 2016). As such, courts are uniquely positioned to promote healing (Marsh et al. 2016). However, to do so courts must become trauma-informed (Marsh et al. 2016). At the systematic level, courts can adopt practices like Project ONE, which emphasize the need for one family - one judge despite which system the injured parties appear in (delinquency, dependency, etc.) (Marsh and Dierkhising 2013). One family - one judge is a practice in which a family (parents and children) have their case(s) heard by one judge only, regardless of whether it is delinquency, dependency, criminal, etc. for as long as the family is in the system. Project ONE recognizes that individuals in the system typically encounter domestic violence, mental health, substance abuse, or trauma (Marsh and Dierkhising 2013). Moreover, Project ONE acts as a trauma reducer by limiting the number of times that individuals must recount trauma (which could trigger prior trauma).

At a more individual level, courts can move away from the "sick-well" and "victim-offender" dichotomy and view all parties with universal precaution as "injured" (Marsh and Dierkhising 2013). This public health perspective reframes thoughts and responses so that they promote health and recovery (Marsh and Dierkhising 2013). This can be done through providing sensitive environments, practices which reflect an understanding of trauma, and policies to promote healing (Marsh and Dierkhising 2013). Additionally, judges and other court officials need to be educated and trained on the impact that trauma can have on human development (Buffington et al. 2010; Marsh et al. 2016). Court personnel must be able to recognize the deleterious effects that trauma can have on human development across social, psychological, and biological domains (Marsh et al. 2016). Furthermore, personnel must create a shared definition of what it means to be trauma-informed; different court personnel, such as attorneys and caseworkers, may perceive different aspects of legal processes to be stressors (Weisz et al. 2013) which could influence their perceptions of the extent to which the court is trauma-informed.

Becoming trauma-informed and utilizing trauma-informed practices is important for court personnel; being able to identify and address trauma in the child abuse and neglect court population will put the court into the position to promote healing. Furthermore, identifying differences across jurisdiction size in whether dependency courts are trauma-informed could identify areas of traumainformed practices that need to be better addressed to limit re-traumatization and promote healing. 


\section{Therapeutic Jurisprudence}

Therapeutic jurisprudence is a concept that suggests that legal actors take into account the well-being of those affected by the law or legal actions (Wexler and Winick 1996). Legal actors consider the possible causes of the crime (e.g., the criminal is addicted to drugs, is homeless, has mental health problems) and whether the legal action will be therapeutic, while not foregoing legal or justice considerations (e.g., deterrence, retribution; Wexler and Winick 1996). For instance, many drug courts are founded on therapeutic jurisprudence principles. These courts do not simply punish the offender, but instead require him to go to drug treatment, take periodic drug tests, maintain employment or seek education, and other criteria. Failure to comply with the court orders could lead to sanctions or prison time. This addresses the underlying drug problem and ultimately is intended to reduce recidivism.

The notion of therapeutic jurisprudence can be applied to child abuse and neglect courts. As discussed above, abused and neglected children have suffered trauma that can negatively affect many areas of their well-being. Being involved in the legal system can re-traumatize them (e.g., by having to face their abuser). However, the courts can minimize the retraumatization through many practices which adhere to the principles of therapeutic jurisprudence. The therapeutic jurisprudence framework can provide guidance for court personnel when interacting with individuals in a court setting.

\section{Limiting Re-Traumatization}

Courts can help limit re-traumatization through several means, including at the person, practice, environment, and policy levels to create a more trauma-informed court environment (Marsh et al. 2016). On the person level, the first thing court personnel can do is create a mutual definition of trauma. This task can open up dialogue about this complex issue and signal to court personnel the importance of becoming trauma-informed. Second, court personnel can prioritize secondary traumatic stress by recognizing it and supporting each other. This task allows courts to assist personnel by identifying support resources as well as creating a space to relax and decompress. Third, court personnel can gather opinions from community members to get an outside perspective on aspects of the justice system which might be unduly stressful. Certain traumatizing aspects of the court process or environment might not be apparent to court personnel; identifying and addressing these stressors can limit further trauma. Fourth, courts can promote diversity in court personnel to create an environment in which staff is demographically similar to the population it serves. This task can create a sense of understanding and responsiveness so that the population feels safe (Marsh et al. 2016).

On the practice level, the first thing court personnel can do is match services to the youth and families' unique needs
(Marsh et al. 2016). This task can promote healing by making individuals feel valued as well as enhance resiliency and reduce stress. The second thing court personnel can do is create positive interactions with the court through actions such as directly addressing the individuals and allowing the individuals to be heard. This task promotes healing by engaging individuals in the process to reduce stress and help them feel heard, valued, and safe. This task aligns with procedural justice literature on the importance of individuals feeling respected and like they have a voice in the system (Lind and Tyler 1988). The third thing court personnel can do is to examine how to implement trauma screenings. This task can limit further trauma by identifying traumatic histories, accurately diagnosing families, and identifying ways to serve them in order to support healing (Marsh et al. 2016).

On the environment level, the first thing court personnel can do is to provide separate waiting rooms for victims and accused perpetrators to ensure that individuals feel safe (Marsh et al. 2016). This task provides victims and perpetrators separate areas and eliminates opportunities for intimidation and threats (Marsh et al. 2016). The second thing court personnel can do is to create an environment which limits arousal and frustration (Marsh et al. 2016). This task can be achieved by addressing factors such as navigability, temperature, lighting, noise levels, and seating (Marsh et al. 2016). On the policy level, courts can adopt practices like Project ONE which emphasize the need for one family - one judge despite which system the injured parties appear in (delinquency, dependency, etc.) (Marsh and Dierkhising 2013). This policy change can act as a trauma reducer by limiting the number of times that individuals must recount trauma (which could re-traumatize them). Each of these tasks could help courts limit re-traumatization at the person, practice, environment, and policy levels to create a more traumainformed court (Marsh et al. 2016). However, different courts do not serve the same populations or have the same resources; as such, there might be key differences in how trauma-informed courts are, particularly when comparing larger and smaller jurisdictions.

\section{Urban versus Rural Settings and Trauma}

It is important to consider jurisdiction population size because population size is an important dimension of urbanicity. Urbanicity is important because due to different landscapes and locations, urban and rural areas encounter differing availability of resources (McCall-Hosenfeld et al. 2014); thus, we must consider where the court falls on the rural-urban continuum. The rural-urban continuum is a continuous scale that ranges from rural villages to big cities. One way to determine where an area or town is on the rural-urban continuum is by population size. The position on the rural-urban continuum is associated with several sociodemographic factors (McCall- 
Hosenfeld et al. 2014). Individuals in rural settings typically have lower incomes, lower educational status (Ricketts et al. 1999), are older (Pruitt and Showman 2014), and are more likely to be uninsured than individuals in urban settings (Schur and Franco 1999). Rural individuals are also more likely to describe themselves as having poor health and more chronic conditions than urban individuals (Schur and Franco 1999). Access to healthcare in rural areas might be complicated by other factors, such as different patterns of employment and insurance coverage (Schur and Franco 1999). Rural individuals are more likely to be employed by smaller entities or self-employed (Schur and Franco 1999). Furthermore, insurance benefits might be less available or generous (Schur and Franco 1999). Rural individuals are more likely to pay a higher percentage for their insurance premiums when based upon income and have less coverage than urban individuals (Schur and Franco 1999). Travel issues could also affect rural individuals' access to services more due to longer travel times and distances to doctors' offices (Annan 2011; Schur and Franco 1999). Due in part to these disparities, individuals in rural settings have an increased frequency of mental illnesses (McCall-Hosenfeld et al. 2014; Probst et al. 2006). However, rural individuals experience deficits in mental healthcare due to a lack of resources, services, or transportation (Annan 2011).

One possibly important factor in the rural-urban mental health disparity is the difference in frequency of trauma exposures (McCall-Hosenfeld et al. 2014). However, research indicates that out of a wide range of trauma exposures, the only rural-urban difference is for war-related trauma which decreased with rurality (McCall-Hosenfeld et al. 2014). The authors suggest that this difference might be due to United States epidemiology in which less than a third of veterans reside in rural settings (McCall-Hosenfeld et al. 2014). The other trauma exposure categories (i.e., accident-related trauma, disasterrelated trauma, interpersonal trauma) were not significantly associated with the individual's geographic location on the urban-rural continuum (McCall-Hosenfeld et al. 2014). Although rural and urban communities have similar frequencies of trauma exposure, rural communities suffer from a shortage of services, which calls for improved access to mental health care for rural communities (McCall-Hosenfeld et al. 2014; Shamblin et al. 2016).

Rurality might affect knowledge of trauma as well as court policy, practice, and environment due to different obstacles being encountered (National Center for State Courts n.d.). Rural courts encounter obstacles such as reduced training opportunities; limited resources, funding, and guidance; isolation; and outdated technology (National Center for State Courts n.d.). Urban courts typically do not face such challenges (National Center for State Courts n.d.). Rural courts also have limited resources for the individuals they serve (Nugent-Borakove et al. 2011) particularly in the areas of services. Court personnel in rural courts face additional problems such as professional isolation, on-going interpersonal relationships with individuals of local communities (which can lead to ethical issues), and the need for court personnel to have a broad range of skills and knowledge as they are involved in many areas of court management (Mahoney et al. 2006). Furthermore, training opportunities, resources, and technology are often developed for use in urban courts, making them inappropriate for rural courts (Mahoney et al. 2006). Additionally, rural courts face outdated facilities, which can create security issues (Mahoney et al. 2006). Older court facilities in rural areas are often incompatible with modern technology, cramped, and poorly ventilated and heated (Mahoney et al. 2006). These obstacles that rural courts face can limit how trauma-informed the court can be in the areas of environment and court personnel's knowledge of trauma.

\section{Overview of the Analysis}

Trauma-informed practice, policy, and environment based on principles of therapeutic jurisprudence can create an atmosphere conducive to healing. Yet, little research has systematically examined the current state of practice in dependency courts (i.e., courts working with children and families). Nor has research fully explored how courts might vary on these dimensions based on whether the court is located in a jurisdiction with a larger or smaller population. This analysis addressed these gaps in the literature by identifying differences in trauma-informed policy, practice, and environment between dependency courts in larger and smaller jurisdictions. Results could inform court personnel as to what areas of trauma-informed practices need to be better addressed in larger and smaller jurisdictions to limit re-traumatization.

Researchers from the National Council of Juvenile and Family Court Judges (NCJFCJ) gathered data from child abuse and neglect courts around the country through a SurveyMonkey.com online survey. It was hypothesized that personnel in smaller jurisdictions would have a lower understanding of trauma and would perceive their courts to be less trauma-informed in the areas of policy, practice, and environment. A lower understanding of trauma was defined as less knowledge about how to identify trauma and its effects in individuals, in addition to less knowledge on how to appropriately address it. Smaller jurisdiction size might affect understanding of trauma as well as court policy, practice, and environment due to different obstacles such as reduced training opportunities, limited resources, funding, and guidance, isolation, and outdated technology (National Center for State Courts n.d.). 


\section{Method}

The present analysis examined four different dependent variables: participants' understanding of trauma, perception of their court's trauma-informed policies, perceptions of their court's trauma-informed practices, and perception of their court's trauma-informed environment. The analysis utilized secondary data from an online survey of child abuse and neglect court professionals in 22 jurisdictions.

\section{Participants}

Participants $(n=1592)$ were recruited after their court requested a trauma consultation from NCJFCJ. Demographic information on gender and age was not gathered and thus could not be assessed. Court personnel from each judicial district were surveyed including, judicial officers (7.7\%), court staff (12.3\%), parent's attorneys (5.8\%), advocates for the child (guardian ad litem, child's attorney; 11.1\%), state or agency attorneys $(4.1 \%)$, social workers/social work supervisors (13.5\%), court appointed special advocates (CASA; 6.4\%), treatment providers (3.6\%), juvenile probation/parole officers $(11.7 \%)$, detention staff $(1.2 \%)$, educators $(1.6 \%)$, and domestic violence advocates $(1.8 \%)$. If the population that the district served was less than 68,000 , the jurisdiction was coded as smaller. The next highest district population was greater than 154,000 and jurisdictions above this population number were classified as larger. In all, $88.5 \%$ of participants served a larger district.

\section{Procedure}

Researchers from NCJFCJ gathered data from child abuse and neglect courts around the country through SurveyMonkey.com. Court personnel were sent a link to the survey which connected them to the SurveyMonkey.com survey. The survey used a semi-snowball technique starting with the lead judge in the area who was asked to disseminate it to other professional offices and their staff, thus response rate was indeterminable. Participants were asked to complete the survey in one sitting and were given approximately two weeks to complete the survey. These data were collected across two years.

\section{Materials}

A survey was used to assess perceptions of trauma-informed practices. Participants answered basic demographic questions (described below) about their location (i.e., city/county and state) and the role they played in the court process. Additionally, participants indicated their understanding of trauma and trauma-informed policy, practice, and perceptions.
Demographics The participants identified the city/county and state that their court served. Additionally, participants indicated what role they played in the court process - either judicial officer, court staff, parent attorney, advocate for the child (GAL/child's attorney), state or agency attorney, social worker/social work supervisor, CASA (court appointed special advocate), treatment provider, juvenile probation/parole, detention staff, educator, domestic violence advocate, or other. Participants noted how many trauma topics they were trained on from a given list with the ability to write in others, which resulted in a numerical value representing prior trauma training.

Understanding of Trauma Participants indicated their understanding of trauma on 11 items (see Table 1). These items were used to create an average understanding of trauma scale. Each item used a 5-point Likert type scale from 1 (strongly disagree) to 5 (strongly agree). The scale was reliable with a Chronbach's alpha of 0.86 . Means are reported along with jurisdiction population size group breakdown in Table 1.

Perceptions of Court Policy Participants indicated their perceptions of how trauma-informed their court policies were on 5 items (see Table 2). These items were used to create an average perception of court policies scale. Each item used a 5point Likert type scale from 1 (strongly disagree) to 5 (strongly agree). The scale was reliable with a Chronbach's alpha of 0.77 (the resulting alpha would only increase by 0.02 if one more item was deleted, and the item was deemed important enough to remain in).

Perceptions of Court Practice Participants indicated their perceptions of how trauma-informed their court practices were on 7 items (see Table 3). These items were used to create an average perception of court practices scale. Each item used a 4-point Likert type scale from 1 (never) to 4 (always). The scale was reliable with a Chronbach's alpha of 0.80 .

Perceptions of Court Environment Participants indicated their perceptions of how trauma-informed their court's environment was on 5 items (see Table 4). These items were used to create an average perception of court environment scale. Each item used a 5-point Likert type scale from 1 (strongly disagree) to 5 (strongly agree). The scale was reliable with a Chronbach's alpha of 0.77 (the alpha would not increase with the elimination of any items).

\section{Results}

The independent variable (whether the dependency court's jurisdiction was larger or smaller) was dummy coded with the reference group being the larger jurisdiction dependency 
Table 1 Understanding trauma measure

\begin{tabular}{|c|c|c|c|c|}
\hline & Mean & Small & Large & $p$ \\
\hline $\begin{array}{l}\text { Clear communication between cross-systems partners is crucial for } \\
\text { a trauma-responsive system to be effective. }\end{array}$ & 4.56 & 4.62 & 4.55 & .26 \\
\hline I am confident in my ability to help a client who has experienced trauma. & 3.48 & 3.57 & 3.47 & .15 \\
\hline $\begin{array}{l}\text { Implementing trauma-informed practices will improve the well-being } \\
\text { of children and families in my jurisdiction. }\end{array}$ & 4.47 & 4.53 & 4.47 & .30 \\
\hline $\begin{array}{l}\text { It is important for staff to periodically update their knowledge regarding } \\
\text { trauma. }\end{array}$ & 4.47 & 4.59 & 4.45 & .01 \\
\hline $\begin{array}{l}\text { I have a clear understanding of what trauma informed practice means } \\
\text { to my professional role. }\end{array}$ & 3.47 & 3.67 & 3.44 & .007 \\
\hline I fully understand how trauma affects parenting. & 3.25 & 3.68 & 3.50 & .03 \\
\hline I understand the impact of trauma on a child's behavior. & 3.93 & 4.05 & 3.91 & .07 \\
\hline $\begin{array}{l}\text { I am confident I could identify posttraumatic reactions in the clients I } \\
\text { serve. }\end{array}$ & 3.26 & 3.32 & 3.25 & .38 \\
\hline $\begin{array}{l}\text { I am aware of the evidence-based practices available in my jurisdiction } \\
\text { to help those who have experienced trauma. }\end{array}$ & 3.01 & 3.16 & 3.00 & .07 \\
\hline $\begin{array}{l}\text { There are resources available to me when I feel overwhelmed working } \\
\text { with my clients. }\end{array}$ & 3.30 & 3.49 & 3.27 & .02 \\
\hline I am aware of how domestic violence affects parenting behaviors. & 3.99 & 4.25 & 3.94 & .00 \\
\hline Understanding scale average & & 3.94 & 3.75 & $<.01$ \\
\hline
\end{tabular}

courts. An independent samples t-test was run to determine whether larger or smaller courts were more trauma-informed in the areas of trauma knowledge, as well as perceptions of court policy, practice, and environment. Assumptions were assessed and met. A linear regression was run to determine if jurisdiction size predicted the number of trauma topics on which court personnel had been trained. Tolerance values were all above 0.01 , VIF values below 5, and the condition index below 30. An examination of the standardized residual histogram and normal P-P plot indicated the normality of the residuals was adequate. The scatterplot of the standardized residuals indicated that the assumptions of homogeneity of variance and independence of residuals were met.

Understanding of Trauma Respondents in smaller jurisdictions had a significantly higher understanding of trauma compared to larger jurisdictions, $t(1050)=-3.60, p<.01$ (Table 1). However, respondents in smaller and larger jurisdictions were not significantly different on every item.
Perceptions of Court Policy Respondents in smaller jurisdictions had a significantly higher perception of how traumainformed their court policies were compared to those in larger jurisdictions, $t(1369)=-5.09, p<.01$ (Table2). Respondents in smaller jurisdictions were significantly different from those in larger jurisdictions on every item.

Perceptions of Court Practice Respondents in smaller jurisdictions had a significantly higher perception of how traumainformed their court practices were compared to larger jurisdictions, $t(1250)=-5.95, p<.01$ (Table 3). Respondents in smaller and larger jurisdictions were significantly different on every item.

Perceptions of Court Environment Respondents in smaller jurisdictions had a significantly higher perception of how trauma-informed their court environment was compared to respondents in larger jurisdictions, $t(1340)=-4.98, p<.01$ (Table 4). However, respondents in smaller and larger jurisdictions were not significantly different on every item.
Table 2 Perceptions of court policy measure

\begin{tabular}{lllll}
\hline & Mean & Small & Large & $p$ \\
\hline Written policy is established committing to trauma responsive practices. & 2.81 & 3.06 & 2.78 & .001 \\
It is the policy of my organization to regularly screen clients for trauma. & 2.88 & 3.13 & 2.85 & .003 \\
$\begin{array}{l}\text { In my organization, the policies regarding working with clients include } \\
\quad 3.45\end{array}$ & 3.84 & 3.40 & .000 \\
$\begin{array}{l}\text { M focus on promoting resilience and general well-being. } \\
\quad \text { associated with working with clients who have experienced trauma. }\end{array}$ & 3.47 & 2.71 & 2.44 & .002 \\
$\begin{array}{l}\text { The diversity in my organization reflects the populations we serve. } \\
\text { Court policy average }\end{array}$ & & 3.58 & 3.18 & .000 \\
\hline
\end{tabular}


Table 3 Perceptions of court practice measure

\begin{tabular}{lllll}
\hline & Mean & Small & Large & $p$ \\
\hline Clients are routinely screened for trauma using a standardized tool. & 2.01 & 2.41 & 1.96 & .000 \\
$\begin{array}{l}\text { Efforts are made to minimize the stressful aspects of the child } \\
\text { protection case process. }\end{array}$ & 2.43 & 2.77 & 2.39 & .000 \\
$\begin{array}{l}\text { An understanding of the impact of trauma is incorporated into daily } \\
\quad \text { decision-making practice at my agency. }\end{array}$ & 2.38 & 2.68 & 2.34 & .000 \\
$\quad \begin{array}{l}\text { Families and children are given systematic opportunity to voice } \\
\text { needs, concerns, and experiences. }\end{array}$ & 2.82 & 3.20 & 2.77 & .000 \\
$\begin{array}{l}\text { Parents and children are treated with respect. } \\
\text { Systems stakeholders treat each other with respect. }\end{array}$ & 3.33 & 3.53 & 3.30 & .000 \\
I discuss trauma issues with cross-systems partners. & 2.87 & 3.01 & 2.85 & .024 \\
Practices scale average & & 2.51 & 2.33 & .018 \\
\hline
\end{tabular}

Trauma Training-Number of Topics The number of trauma topics on which respondents were trained was used as a control variable. The linear regression was not significant, $F(1,1590)=0.52, p=0.47, \mathrm{R}^{2}<.01$. The total number of trauma topics for which respondents from courts in smaller jurisdictions had received training was not significantly different than respondents from courts in larger jurisdictions.

\section{Discussion}

The purpose of this analysis was to determine if dependency court personnel in larger and smaller jurisdictions differ in their understandings of trauma, perceptions of court policies, perceptions of court practices, and perceptions of court environment. It was hypothesized that those in smaller jurisdictions would have a lower understanding of trauma and would perceive their courts to be less trauma-informed in the areas of policy, practice, and environment than those in larger jurisdictions. The results do not support this hypothesis. The results indicate that personnel in dependency courts in smaller jurisdictions have a higher understanding of trauma compared to larger jurisdiction court personnel. Smaller jurisdiction court personnel reported more knowledge of how to identify trauma and its effects in individuals, as well as more understanding of how it can be addressed appropriately. These findings are contrary to previous studies (Mahoney et al. 2006; National
Center for State Courts n.d.) that found that courts in rural or smaller jurisdictions encounter obstacles such as a shortage of services, reduced training opportunities, limited resources, funding, and guidance, isolation, and outdated technology compared to courts in urban or larger jurisdictions. These findings, albeit contrary to expectation, can still be useful in understanding the nature of trauma-informed court practice.

In general, personnel in both larger and smaller jurisdictions had a high understanding of trauma, which can particularly be seen in items like: "clear communication between cross-systems partners is crucial for a trauma-responsive system to be effective," "implementing trauma-informed practices will improve the well-being of children and families in my jurisdiction," and "it is important for staff to periodically update their knowledge regarding trauma." However, both groups of court personnel had low perceptions of court practice, which can particularly be seen in items like: "clients are routinely screened for trauma using a standardized tool," "I discuss trauma issues with cross-systems partners," "an understanding of the impact of trauma is incorporated into daily decision-making practice at my agency," and "efforts are made to minimize the stressful aspects of the child protection case process."

There was no difference between court personnel in larger and smaller jurisdictions on the number of trauma topics trained on which is contrary to what was expected. As discussed previously, the literature suggests that rural/smaller courts encounter obstacles such as reduced training
Table 4 Perceptions of court environment measure

\begin{tabular}{lllll}
\hline & Mean & Small & Large & $p$ \\
\hline The courtrooms are child friendly. & 2.96 & 3.20 & 2.93 & .005 \\
The courthouse is easy to navigate for the families. & 3.08 & 3.68 & 3.01 & .000 \\
Adult and child victims have a safe place to wait that is separate & 2.99 & 3.31 & 2.95 & .000 \\
$\quad$ from their perpetrator. & 3.59 & 3.72 & 3.57 & .100 \\
All parties are treated with respect while at court. & 3.84 & 4.07 & 3.82 & .002 \\
I feel safe when I am at the courthouse. & & 3.59 & 3.26 & $<.01$ \\
Environment scale average & & & &
\end{tabular}


opportunities which larger/urban courts do not (National Center for State Courts n.d.). The results indicate that respondents in smaller jurisdiction courts in the present analysis are not experiencing these obstacles as a result of their jurisdictions' smaller population size and possible rurality. Additionally, there were no differences in the items related to the importance of being trauma-informed. Respondents in both smaller and larger jurisdiction courts in indicated that clear communication between stakeholders is important in being trauma-informed and that being trauma-informed can lead to better outcomes for children and youth. There was also no difference in respondents' confidence in being able to identify post-traumatic symptoms and help victims of trauma. Whether from courts in smaller or larger jurisdictions, respondents were fairly neutral in these statements, unsure that they had or did not have the ability to identify or help victims. This would indicate that regardless of training, not all personnel feel able to identify and work with trauma-victims and more support could be provided here. Additionally, dependency court personnel, regardless of jurisdiction population size, indicated that clients are not routinely being screened for trauma using a standardized tool. All courts could benefit from the consistent use of a standardized screening tool which might enhance their understanding of clients' trauma. In addition, courts could benefit from assessments regarding perceptions of how trauma-informed their court is in the areas of policy, practice, and environment.

Despite a few similarities between courts in larger and smaller jurisdictions, the majority of items and all of the combined scales were significantly different between the groups. Personnel in smaller jurisdiction courts had a higher perception of how trauma-informed their court's policies, practices, and environment were compared to larger jurisdiction personnel. This can particularly be seen in items such as: "in my organization, the policies regarding working with clients include a focus on promoting resilience and general wellbeing," "the diversity in my organization reflects the populations we serve," "families and children are given systematic opportunity to voice needs, concerns, and experiences," and "the courthouse is easy to navigate for the families."

Although these results are contrary to what was hypothesized based on of previous research, the results indicate potential alternative explanations. The results might indicate that smaller jurisdiction courts are recognizing their extra obstacles and shortages of resources and services. Furthermore, the results might indicate that smaller jurisdiction courts are having to accommodate within their court, rather than refer individuals to services (like larger jurisdiction courts might) that are unavailable due to the relative rurality of the environment.

The results could also be due to difference in population characteristics that courts with different size populations serve. Larger jurisdiction courts serve a more diverse population and intervention is often more formal and process- oriented (Feld 1991). Conversely, smaller jurisdiction courts serve a more homogeneous population and intervention is procedurally less formal (Feld 1991). Courts in smaller jurisdictions might be able to commit more time toward addressing trauma and staff burnout due to less formal procedures. Their smaller population may also provide an advantage. With key stakeholders that rarely change, all court personnel might know each other and the families before them on a personal level, which could encourage open communication and collaboration between parties, and increase understanding and compassion for the families they serve. This could be a cultural difference between smaller and larger jurisdictions. With smaller towns, court personnel may have developed familiarity and relationships with families and service providers that increase communication and awareness of available resources. Furthermore, smaller jurisdiction courts serve a more homogeneous population which allows them to form a staff which reflects the population in which they serve.

The results might also be explained in part by the culture of the courts and their workloads. Some studies have suggested that larger, more urban courts have higher workload (Dobbin et al. 2010). This could indicate that such courts have less time to spend on cases, as well as less time to devote to making sure the environment and practice are appropriate to serve the needs of victims. The pace of cases might therefore differ. With an overcrowded docket, larger, more urban courts might rush through cases and have packed waiting rooms. Smaller, more rural courts may have fewer cases, and subsequently more time to spend on each one and fewer people in the waiting room. The smaller, slower paced more rural courts could, therefore, feel safer, easier to navigate, and allow victims to find a safe place to wait away from their alleged perpetrator. Additionally, smaller courts might have less formal procedures as a result of a lower caseload; this allows court personnel to more easily tailor the policies, practices, and environment to address trauma.

\section{Implications}

The results could indicate that court personnel and courts in smaller jurisdictions are more trauma-informed or just that they perceive their court to be highly trauma-informed. At present, there is no research that addresses the reality of the degree to which courts actually are trauma-informed, and as such should be an avenue for future research.

These results can inform applied researchers and court personnel about their perceptions of trauma understanding as well as trauma-informed policy, practice, and environment in larger and smaller jurisdiction court settings. These results suggest courts in smaller jurisdictions have a higher understanding of trauma as well as perceive their courts to have a high level of trauma-informed policies, practices, and environment. Applied researchers and court personnel can use these results 
to inform interactions with courts in different types of jurisdictions. These results could inform NCJFCJ and other court and agency trauma trainings - trainers should be aware that in general, smaller jurisdiction court personnel may be more trauma-informed. As such, trainers might not have to spend as much time training smaller jurisdiction court personnel in the areas of policies, practices, and environment. Additionally, trauma trainers might emphasize what can be done to become trauma-informed at the person, practice, environment, and policy levels more to personnel in larger jurisdiction courts. Trauma trainers could encourage personnel in larger jurisdiction courts to slow down the pace and take more time on each case to ensure practice is more trauma-informed. Trauma trainers could more closely examine the court practice and environment to determine if structures could be put into place to ensure that youth and families can better navigate and feel safe when attending court hearings.

The results also have implications for therapeutic jurisprudence. Since smaller, more rural courts typically have less formal procedures, they might have more room to tailor the legal action to the underlying problem (taking a more therapeutic approach). Trauma trainers could encourage larger courts to do the same by loosening up their formal procedures to create a more therapeutic approach. Overall, the results indicate that there are significant differences between child abuse and neglect courts by jurisdiction size in the areas of trauma understanding, policy, practice, and environment which indicates that population size is an important factor in courts being trauma-informed. Thus, population size and rural/urban designation should be further examined. The therapeutic jurisprudence framework can provide guidance for court personnel when interacting with individuals in a court setting. Court personnel should consider their effect on individuals the law affects. Thus, the therapeutic jurisprudence framework would recommend that judges engage in service mapping as a way to identify all available services for families to ensure that each family's unique needs are met. Additionally, the framework would recommend engaging in conversations in a different way, such as moving away from "what is wrong with you?" to "what happened to you?" (Child Welfare Information Gateway 2015).

In addition to population size differences in court practice (or perceptions), the survey findings also point toward some areas of infrequent practice across sites. For example, although smaller jurisdiction court personnel were significantly more likely than larger jurisdiction court personnel to say that they screen victims for trauma, this still only fell at the "sometimes" mark, indicating that across the different jurisdictions, parents and youth are rarely screened for trauma. If screening is not occurring, then many trauma victims might not be properly identified or treated within the court system. As trauma screening is recommended for youth and families to ensure their needs are best met; this is something that should be addressed across sites to better learn why it is not occurring and how sites are working with families to best meet their complex needs. In addition, another area that had low agreement was the statement that policies are in place to reduce burnout. On average, across courts, most were between neutral or disagreement with this statement. This indicates that most courts do not have policies in place to address secondary trauma, compassion fatigue, and burnout. These are critical elements of a trauma-informed court. Experiencing secondary trauma through hearing about a child or family's traumatic experience can lead to physical and mental health concerns for professionals (Marsh et al. 2016; National Child Traumatic Stress Network 2011) and could affect their decision-making on cases. Self-care is an important element in cases and barriers to secondary stress should be integrated into practice in all courts to protect the professionals (Miller and Bornstein 2013).

\section{Limitations}

Although there are limitations of the present analysis, these results provide a fuller picture of how courts might vary based on whether the court is located in a jurisdiction with a larger or smaller population. The first limitation of the present analysis is the use of secondary data. This methodology limits the questions that can be asked and the answers that can be found from this dataset. The second limitation is that this analysis does not use a representative sample of child abuse and neglect courts across the United States which can affect generalizability. The third limitation is that only child abuse and neglect courts were examined, which limits the generalizability to child abuse and neglect courts only. The fourth limitation is that all the courts in this dataset were recruited as a result of requesting a trauma audit from NCJFCJ which could affect the results. This sample might not adequately represent all child abuse and neglect courts in the United States. Courts who requested a trauma audit could be more aware of trauma and more willing to participate in trauma-informed practices than court personnel who were not surveyed.

The fifth limitation is that the data assesses court personnel's perceptions of being trauma-informed rather than actual measures of how trauma-informed their court actually is, which limits the implications of the conclusions that can be drawn. Although the results indicate that personnel in smaller, more rural courts have a greater understanding of trauma and trauma-informed practices, as well as perceive their policies, practices, and environment to be more trauma-informed, these perceptions might be inaccurate. Literature suggests that rurality might affect knowledge of trauma, in addition to court policy, practice, and environment due to different obstacles such as reduced training opportunities; limited resources, funding, and guidance; isolation; and outdated technology (National Center for State Courts n.d.). Thus, due to the 
secondary nature of data, there is no way to say whether smaller, more rural courts are actually less trauma-informed. The results only indicate that personnel in smaller courts perceive their courts to be more trauma-informed than personnel in larger court jurisdictions. This discrepancy could imply that current results do not reflect actuality. As such, future research should explore how trauma-informed courts actually are, rather than court personnel's perceptions of how trauma-informed their court is. The present analysis addresses a gap in the literature and provides an important stepping stone for this future research.

\section{Future Directions}

One avenue for future research could be a quasi-experiment which gathers a representative sample of all types of courts (not just child abuse and neglect courts) in both smaller and larger jurisdictions. Half of the participants would be assigned to receive trauma training and then have their court assessed for how trauma-informed they are. The other half of the participants would not receive trauma training, but would have their court assessed for how trauma-informed they are. Researchers would do an assessment of how traumainformed their court actually is rather that giving participants a survey to determine their perceptions of how traumainformed their court is. Results would indicate how traumainformed smaller and larger jurisdictions are when no training is received and when training is received. This research design would address several of the previously discussed limitations of the present analysis. First, the data would not be secondary and as such the appropriate questions could be asked to assess how trauma informed larger versus smaller courts actually are. Second, the analysis would gather a representative sample of courts in the United States. Third, the analysis would assess all types of courts, not just child abuse and neglect courts. Fourth, courts would not be recruited based on their request for trauma training; rather, participating courts would be recruited based off their larger/smaller jurisdiction designation. As the proposed analysis addresses nearly all the limitations of the present analysis, it would act as a good area for future research to truly flesh out the results of the present analysis.

\section{Conclusion}

Individuals in the child abuse and neglect system are already traumatized and can be re-traumatized by court practices, programs, and environment. However, courts can take a therapeutic jurisprudence approach to limit these negative outcomes by creating trauma-informed policies, practices, and environment within their court. The results of the present analysis indicate that smaller jurisdiction court personnel have a higher understanding of trauma and perceive their courts to have more trauma-informed policies, practices, and environment when compared to larger jurisdiction court personnel. Future research needs to be conducted in order to further understand the results of the current analysis. If child abuse and neglect courts engage in trauma-informed strategies, then these courts can better serve their populations and limit the effects of trauma on child development.

\section{Compliance with Ethical Standards}

Ethical Approval All procedures followed were in accordance with the ethical standards of the responsible committee on human experimentation (institutional and national) and with the Helsinki Declaration of 1975, as revised in 2000 .

Informed Consent Informed consent was obtained from all patients for being included in the study.

\section{References}

Annan, S. L. (2011). "It's not just a job. This is where we live. This is our backyard": The experiences of expert legal and advocate providers with sexually assaulted women in rural areas. Journal of the American Psychiatric Nurses Association, 17(2), 139-147. https://doi.org/10.1177/1078390311401024.

Buffington, K., Dierkhising, C. B., \& Marsh, S. C. (2010). Ten things every juvenile court judge should know about trauma and delinquency. Juvenile and Family Court Journal, 61(3), 13-23. https://doi.org/10.1111/j.1755-6988.2010.01044.x.

Chapman, J., Ford, J. D., Albert, D., \& Hawke, J. (2006). Traumatic stress: Exposure, identification, and intervention in correctional systems. Administration and Management of Correctional Health Care, 2.

Child Welfare Information Gateway (2015). Developing a traumainformed child welfare system. Retrieved from https://www. childwelfare.gov/pubpdfs/trauma_informed.pdf

Child Welfare Information Gateway (2017). Child maltreatment 2015: Summary of key findings. Retrieved from https:// www.childwelfare.gov/pubpdfs/canstats.pdf

Dierkhising, C. B., Ko, S. J., Woods-Jaeger, B., Briggs, E. C., Lee, R., \& Pynoos, R. S. (2013). Trauma histories among justiceinvolved youth: Findings from the national child traumatic stress network. European Journal of Psychotraumatology, 4, 1-12. https://doi.org/10.3402/ejpt.v4i0.20274.

Dobbin, S., Gatowski, S., Russell, J., \& Summers, A. (2010). Judicial workload in Washington state dependency cases. Retrieved from https://www.ncjfcj.org/resource-library/publications/judicialworkload-washington-state-dependency-cases

Feld, B. C. (1991). Justice by geography: Urban, suburban, and rural variations in juvenile justice administration. The Journal of Criminal Law and Criminology, 82(1), 156-210.

Foy, D. W., Ritchie, I. K., \& Conway, A. H. (2012). Trauma exposure, posttraumatic stress, and comorbidities in female adolescent offenders: Findings and implications from recent studies. European Journal of Psychotraumatology, 3, 17247. https://doi.org/10.3402/ ejpt.v3i0.17247.

Garland, A. F., Hough, R. L., McCabe, K., Yeh, M., Wood, P. A., \& Aarons, G. A. (2001). Prevalence of psychiatric disorders in youths across five sectors of care. Journal of the American Academy of Child \& Adolescent Psychiatry, 40, 409-418. https://doi.org/10. 1097/00004583-200104000-00009. 
Kerig, P. K., Ward, R. M., Vanderzee, K. L., \& Moeddel, M. A. (2009). Posttraumatic stress as a mediator of the relationship between trauma and mental health problems among juvenile delinquents. Journal of Youth and Adolescence, 38, 1214-1225. https://doi.org/10.1007/ s10964-008-9332-5.

Ko, S. J., \& Sprague, C. (2007). Creating trauma-informed child-serving systems. NCTSN Service Systems Briefs v1 n1. Retrieved December 7, 2016, from: http://nctsn.org/sites/default/files/assets/ pdfs/Service_Systems_Brief_v1_v1.pdf

Ko, S. J., Ford, J. D., Kassam-Adams, N., Berkowitz, S. J., Wilson, C., Wong, M., Brymer, M. J., \& Layne, C. M. (2008). Creating traumainformed systems: Child welfare, education, first responders, health care, juvenile justice. Professional Psychology: Research and Practice, 39(4), 396-404. https://doi.org/10.1037/0735-7028.39.4.396.

Lind, E. A., \& Tyler, T. R. (1988). The social psychology of procedural justice. New York: Plenum.

Mahoney, B., Carlson, A., \& Baehler, A. (2006). Strengthening rural courts: What should be done to improve court operations and enhance the quality of justice in rural America? Court Manager, 20(4), $11-16$.

Marsh, S. C., \& Dierkhising, C. B. (2013). Toward a conceptual framework for trauma-informed practice in juvenile and family courts (pp. 19-20). Spring: Juvenile and Family Justice Today.

Marsh, S. C., Summers, A., DeVault, A., \& Villalobos, J. G. (2016). Lessons learned from developing a trauma consultation protocol for juvenile and family courts. Juvenile and Family Court Journal, 67(3), 5-22. https://doi.org/10.1111/jfcj.12059.

McCall-Hosenfeld, J. S., Mukherjee, S., \& Lehman, E. B. (2014). The prevalence and correlates of lifetime psychiatric disorders and trauma exposures in urban and rural settings: Results from the national comorbidity survey replication. PLoS One, 9(11), 1-11. https://doi.org/10.1371/journal.pone.0112416.

Miller, M. K., \& Bornstein, B. H. (Eds.). (2013). Stress, trauma, and wellbeing in the legal system. New York: Oxford University Press.

National Center for State Courts (n.d.). Rural courts: Resource guide. Retrieved from http:/www.ncsc.org/Topics/Special-Jurisdiction/ Rural-Courts/Resource-Guide.aspx

National Child Traumatic Stress Network, Secondary Traumatic Stress Committee (2011). Secondary traumatic stress: A fact sheet for child-serving professionals. Los Angeles, CA and Durham, NC: National Center for Child Traumatic Stress.

Nugent-Borakove, E., Mahoney, B., \& Whitcomb, D. (2011). Strengthening rural courts: Challenges and progress. Retrieved from http://cdm16501.contentdm.oclc.org/cdm/ref/collection/ ctadmin/id/1843

Probst, J. C., Laditka, S. B., Moore, C. G., Harun, N., Powell, M. P., \& Baxley, E. G. (2006). Rural-urban differences in depression prevalence: Implications for family medicine. Family Medicine, 38(9), $653-660$.
Pruitt, L. R., \& Showman, B. (2014). Law stretched thin: Access to justice in rural America. South Dakota Law Review, 59, 466- 493.

Pynoos, R. S., Steinberg, A. M., Schreiber, M. D., \& Brymer, M. J. (2006). Children and families: A new framework for preparedness and response to danger, terrorism, and trauma. In L. A. Schein, H. I. Spitz, G. M. Burlingame, \& P. R. Muskin (Eds.), Group approaches for the psychological effects of terrorist disasters (pp. 83-112). New York: Haworth Press.

Ricketts, T. C., Johnson-Webb, K. D., \& Randolph, R. K. (1999). Populations and places in rural America. In T. C. Ricketts III (Ed.), Rural health in the United States (pp. 7-24). New York: Oxford University Press.

Schur, C., \& Franco, S. (1999). Access to health care. In T. C. Ricketts III (Ed.), Rural health in the United States (pp. 25-37). New York: Oxford University Press.

Shamblin, S., Graham, D., \& Bianco, J. A. (2016). Creating traumainformed schools for rural Appalachia: The partnerships program for enhancing resiliency, confidence and workforce development in early childhood education. School Mental Health, 8(1), 189200. https://doi.org/10.1007/s12310-016-9181-4.

Smith, C. A., \& Thornberry, T. P. (1995). The relationship between childhood maltreatment and adolescent involvement in delinquency. Washington: Office of Juvenile Justice and Delinquency Prevention. https://doi.org/10.1111/j.1745-9125.1995.tb01186.x.

Substance Abuse and Mental Health Services (2017, December 19). Understanding child trauma. Retrieved from https:/www.samhsa. gov/child-trauma/understanding-child-trauma

Truman, J. L., \& Morgan, R. E. (2016). Criminal victimization 2015. U.S. Bureau of Justice Statistics.

Weisz, V., Beal, S. J., \& Wingrove, T. (2013). The legal system experiences of children, families, and professionals who work with them. In M. K. Miller \& B. H. Bornstein (Eds.), Stress, trauma, and wellbeing in the legal system (pp. 63-88). New York: Oxford University Press.

Wexler, D. B., \& Winick, B. J. (1996). Law in a therapeutic key: Developments in therapeutic jurisprudence. Durham: Carolina Academic Press.

Widom, C. S., \& Maxfield, M. G. (1996). A prospective examination of risk for violence among abused and neglected children. Annals of the New York Academy of Sciences, 794, 224-236. https://doi.org/10.1111/j.1749-6632.1996.tb32523.x.

Wood, J., Foy, D. W., Layne, C., Pynoos, R., \& James, C. B. (2002). An examination of the relationships between violence exposure, posttraumatic stress symptomatology, and delinquent activity: An "ecopathological" model of delinquent behavior among incarcerated adolescents. Journal of Aggression, Maltreatment \& Trauma, 6, 127-147. https://doi.org/10.1300/J146v06n01_07. 